University of Nebraska - Lincoln

DigitalCommons@University of Nebraska - Lincoln

Architectural Engineering -- Faculty Publications

Architectural Engineering and Construction,

Durham School of

$7-2008$

\title{
Implications of Human Performance and Perception under Tonal Noise Conditions on Indoor Noise Criteria
}

\author{
Lily M. Wang \\ University of Nebraska - Lincoln, Iwang4@unl.edu \\ Erica E. Ryherd \\ University of Nebraska - Lincoln
}

Follow this and additional works at: https://digitalcommons.unl.edu/archengfacpub

Part of the Architectural Engineering Commons

Wang, Lily M. and Ryherd, Erica E., "Implications of Human Performance and Perception under Tonal Noise Conditions on Indoor Noise Criteria" (2008). Architectural Engineering -- Faculty Publications. 20. https://digitalcommons.unl.edu/archengfacpub/20

This Article is brought to you for free and open access by the Architectural Engineering and Construction, Durham School of at DigitalCommons@University of Nebraska - Lincoln. It has been accepted for inclusion in Architectural Engineering -- Faculty Publications by an authorized administrator of DigitalCommons@University of Nebraska Lincoln. 


\title{
Implications of human performance and perception under tonal noise conditions on indoor noise criteria
}

\author{
Erica E. Ryherd ${ }^{\text {a) }}$ and Lily M. Wang \\ Architectural Engineering Program, University of Nebraska-Lincoln, 101A Peter Kiewit Institute, \\ 1110 S. 67th St., Omaha, Nebraska 68182-0681
}

(Received 17 September 2007; revised 7 April 2008; accepted 27 April 2008)

\begin{abstract}
This research investigated differences in task performance and perception under six non-time-varying ventilation-type background noise spectra with differing tonality. The results were related to five indoor noise criteria systems: noise criteria, balanced noise criteria, room criteria, room criteria mark II, and the $A$-weighted equivalent sound pressure level $\left(L_{\mathrm{Aeq}}\right)$. These criteria systems are commonly used in the U.S. building industry, but concerns exist over whether they are appropriate for all noise situations. Thirty test subjects completed three types of performance tasks (typing, reasoning, and math) and answered questions about their perception of the indoor environment under each noise condition. Results showed that performance scores did not change significantly across the six noise conditions, but there were differences in subjective perception. For example, perception trends for tonality, annoyance, and distraction changed based on the frequency and prominence of discrete tones in noise. However, these perceptual changes were not fully reflected in the criteria level or spectral quality ratings. Additionally, task performance was related to subjective perception but not to criteria level predictions. As a result, the authors suggest that the current criteria should be modified to account for the frequency and prominence of tones in background noise. (C) 2008 Acoustical Society of America. [DOI: 10.1121/1.2932075]
\end{abstract}

PACS number(s): 43.50.Ba, 43.50.Jh, 43.50.Qp [BSF]

Pages: $218-226$

\section{INTRODUCTION}

An important design consideration of any space is that of background noise, as ambient sound is something building occupants readily encounter in their everyday environments. Heating, ventilating, and air-conditioning (HVAC) systems constitute a primary source of noise and subsequent complaints. Several indoor noise criteria systems are currently used to quantify the background noise in buildings resulting from HVAC systems. Some of the more popular methods are noise criteria $(\mathrm{NC}),{ }^{1}$ balanced noise criteria $(\mathrm{NCB}),{ }^{2}$ room criteria (RC), ${ }^{3}$ room criteria mark II (RC mark II), ${ }^{4}$ and $A$-weighted equivalent sound pressure level $\left(L_{\text {Aeq }}\right){ }^{5}$ These criteria are used by acoustical consultants, noise control engineers, mechanical system designers, architects, and others.

Detailed descriptions and comparisons of these five criteria are available in several sources, i.e., Refs. 6-12. As a brief overview, these systems provide an evaluation of the overall level of noise, given as a single number rating. The rating is found by comparison of the measured background noise to a defined set of sound pressure level versus frequency curves. NCB, RC, and RC mark II also include quality descriptors that give an indication of the spectral character of the sound. NCB and RC indicate the presence of rumble (excessive low frequency energy) and hiss (excessive high frequency energy), as well as noise induced vibration. $\mathrm{RC}$ mark II also indicates the presence of roar (excessive midfrequency energy) and evaluates occupant acceptance

\footnotetext{
${ }^{a)}$ Present address: Woodruff School of Mechanical Engineering, Georgia Institute of Technology, Atlanta, GA 30332-0405. Electronic mail: eryherd@hotmail.com
}

through a calculation of the quality assessment index (QAI). The QAI is found based on the range of energy-averaged spectral deviations between the measured noise and the $\mathrm{RC}$ contour levels.

The criteria are commonly used to set background noise goals and diagnose noise problems in buildings. However, the appropriate applications of these criteria have been called into question due to several factors. Previous studies have shown that there can be large differences among indoor noise criteria predictions for the same spectrum, ${ }^{8,9,13}$ leaving the end user unsure as to which system to rely on. As a result, preferences among building designers and standards as to which criterion to use varies greatly. This is immediately apparent from a review of the criteria guidelines set by several sources. ${ }^{12,14,15}$

Several limitations also exist in the current criteria. A primary shortcoming is insufficient characterization of discrete tones ${ }^{16}$ and variance over time, which are commonly found in building HVAC noise. A project is underway which investigates these limitations in the criteria and evaluates the general ability of these systems to relate to occupant perception and performance under a variety of HVAC noise conditions. This paper discusses one study in the overall project that focused on tonality in background noise.

\section{PREVIOUS RESEARCH}

Several recent studies have investigated the relationship between subjective impression of ambient noise and measured sound spectra, with some evaluation of indoor noise criteria. ${ }^{17-24}$ Ayr et al. examined the effectiveness of several criteria methodologies using questionnaires and in situ office 
noise measurements. They found that $L_{\text {Aeq }}$ generally performed well in evaluating occupation response to ventilation noise. ${ }^{22,23}$ The studies by Tang et al. also found $L_{\text {Aeq }}$ to be generally well correlated with subjective auditory sensation, with other metrics performing well in certain circumstances. ${ }^{18-21}$ Tang and Wang noted that many of their measured spectra contained some degree of tonality, but a detailed investigation of such was not the focus of their work. ${ }^{21}$

Despite these previous studies generally supporting $L_{\text {Aeq }}$, other studies have demonstrated limitations in the metric. ${ }^{17,25}$ Persson et al. demonstrated that annoyance perception differed for ventilation noises with similar $L_{\text {Aeq }}$ ratings but differing low frequency content, ${ }^{17}$ supporting the concept that $L_{\text {Aeq }}$ is less suited for spectra having strong low frequency components. ${ }^{26} \mathrm{Ayr}$ et al. noted that the good performance of $L_{\mathrm{Aeq}}$ in their previously described studies may be in part due to the large number of hissy spectra included. ${ }^{23}$ In addition to the types of noise conditions examined, the differences in comparing previous work can also be partially attributed to the testing methodologies. Regardless, a clear consensus on the performance of the various criteria has not been reached, and additional investigations of their limitations are warranted.

Much work has been conducted on loudness and annoyance of tones in noise, ${ }^{27-32}$ but little has been done to correlate these with commonly used indoor noise criteria systems. Modern HVAC systems are replete with examples of pure tones. Certain types of mechanical equipment, such as motors and fans, can emit lower frequency tones. Research indicates that higher frequency pure tones may also be disturbing. ${ }^{31,32}$

Other research has examined how background noise impacts task performance. Although a lot of work has been done on how high levels of noise affect productivity, ${ }^{33-35}$ the pool of research examining how typical office background noise affects worker performance is more limited. The effect of excessive low frequency background noise on task performance has been the topic of several projects. ${ }^{30,36-43}$ Some of the conclusions from these studies are that task performance can be affected by background noise and the frequency character of the noise is an important consideration. These studies provide important information about the relationship between noise and performance but generally do not relate the results to indoor noise criteria.

The current research expands upon previous work by evaluating the ability of five criteria methods to relate to task performance and subjective perception under ventilation systems-induced background noise. The goal of the research was to investigate whether significant changes in subjective response existed when comparing six noise conditions with differing tonality yet similar criteria rating. The results are used to provide insight into future criteria modifications with regards to tonality.

\section{METHODOLOGY}

\section{A. Testing chamber}

A floor plan of the experimental test chamber is shown in Fig. 1. The room is $26.5 \mathrm{~m}^{3}$ and furnished as a typical

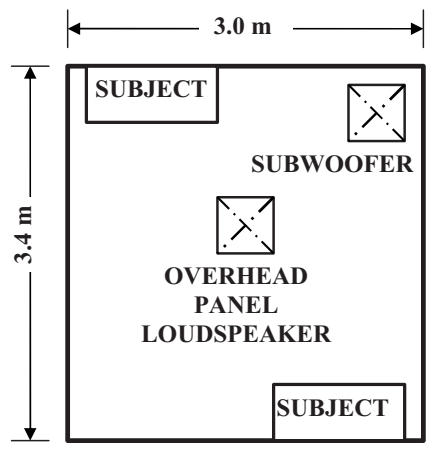

FIG. 1. Plan view of the test chamber setup (not to scale). Floor to ceiling height is $2.6 \mathrm{~m}$.

office with carpet, gypsum board wall construction, and acoustical ceiling tiles. It exhibits a reverberation time of $0.25 \mathrm{~s}$ at $500 \mathrm{~Hz}$. The sound field can be controlled in the test chamber, which has a low naturally occurring $L_{\text {Aeq }}$ of $35 \mathrm{~dB}$. The surrounding structure of the test chamber achieves STC 47 to minimize noise intrusions. To ensure maximum isolation, the spaces immediately surrounding the test chamber were unoccupied during testing, with the exception of a researcher sitting quietly in an adjacent room. The chamber was maintained at comfortable working conditions of approximately $20^{\circ} \mathrm{C}$ and $764 \mathrm{~lx}$ at the work plane.

The intent was to present the noise in such a manner that it would be perceived as similar to typical ventilation systems sound. Noise conditions were presented with an Armstrong iceiling ${ }^{\mathrm{TM}}$ overhead panel loudspeaker that supplied the primary mid- to high frequency energy and a JBL Northridge ${ }^{\mathrm{TM}}$ E250P subwoofer that supplied the primary low frequency energy. Neither loudspeaker was immediately identifiable as audio equipment. The iceiling ${ }^{\mathrm{TM}}$ loudspeakers look like acoustical lay-in ceiling tiles and the subwoofer was covered in acoustically transparent fabric and placed in the corner of the room to resemble an end table. An Armstrong iceiling ${ }^{\mathrm{TM}}$ D2001 digital processor and an Armstrong D4100 amplifier were used for mixing and amplification. At the conclusion of the study, subjects reported that they thought that the noise sounded like mechanical systems, and that it was coming from the ventilation, pipes, or the ductwork.

\section{B. Noise conditions}

The effects of six different background noise conditions were examined. Under each noise condition, subjects completed three types of tests and a subjective perception questionnaire. The noise conditions were presented in random order for each subject. The spectra of the six noise conditions are shown in Figs. 2-5:

(1) Midlevel neutral condition (see Fig. 2): broadband noise, simulated with $-5 \mathrm{~dB} /$ octave band slope, intersecting $40 \mathrm{~dB}$ at $1000 \mathrm{~Hz}$.

(2) $120 \mathrm{~Hz}$ tonal condition, $P R=5$ (see Fig. 3): broadband noise with a tonal component at $120 \mathrm{~Hz}$, measured from an existing facility, with the overall $L_{\text {Aeq }}$ equalized to $47 \mathrm{~dB}$. The prominence ratio (PR) of the tone is $5 .{ }^{44}$ The source was a wall mounted heat pump in cooling mode. 


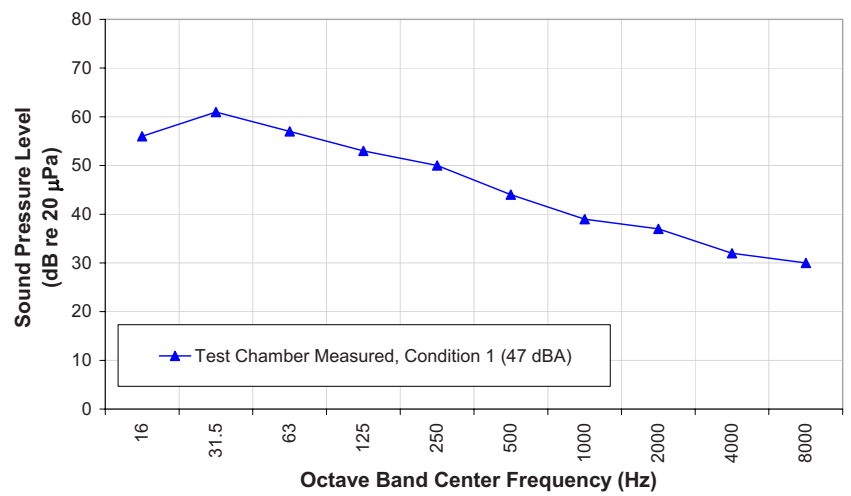

FIG. 2. (Color online) Octave band spectrum of midlevel neutral noise condition (1), as measured in the test chamber.

(3) $120 \mathrm{~Hz}$ tonal condition, $P R=9$ (see Fig. 3): similar to signal 2, with the PR of the tone increased to 9.

(4) $235 \mathrm{~Hz}$ tonal condition, $P R=5$ (see Fig. 4): broadband noise with a tonal component at $235 \mathrm{~Hz}$, measured from an existing facility, with the overall $L_{A \text { eq }}$ equalized to $46 \mathrm{~dB}$. The PR of the tone is 5 . The source was a laboratory fume hood. ${ }^{45}$

(5) $235 \mathrm{~Hz}$ tonal condition, $P R=9$ (see Fig. 4): similar to signal 4, with PR of the tone increased to 9.

(6) $595 \mathrm{~Hz}$ tonal condition, $P R=9$ (see Fig. 5): broadband noise with a tonal component at $595 \mathrm{~Hz}$, measured from an existing facility, with the overall $L_{\text {Aeq }}$ equalized to $47 \mathrm{~dB}$. The PR of the tone is 9 . The source was a screw compressor.

Previous research demonstrates that the sound level affects performance and perception, so to highlight differences due to tones rather than level, all noise conditions in this study were set to a similar overall $L_{\text {Aeq }}{ }^{10,11}$ An important difference between noise condition (2) versus (3) and condition (4) versus (5) is the tonal PR. The PR is a ratio of the power of the critical band centered on a tone compared to the mean power of the two adjacent critical bands. ${ }^{44}$ The 1995 version of the ANSI S1.13 standard states that tones were considered prominent or clearly audible if the PR is greater than or equal to 7 . The noise conditions in this study were selected based on this standard to fall both below and above

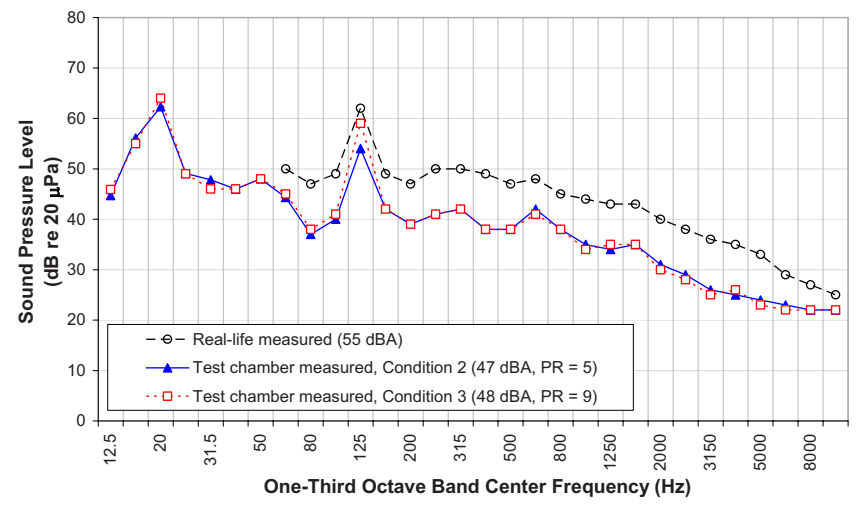

FIG. 3. (Color online) One-third octave band spectrum of $120 \mathrm{~Hz}$ tonal noise conditions (2) $(\mathrm{PR}=5)$ and (3) $(\mathrm{PR}=9)$, as measured in the real installation and the test chamber.

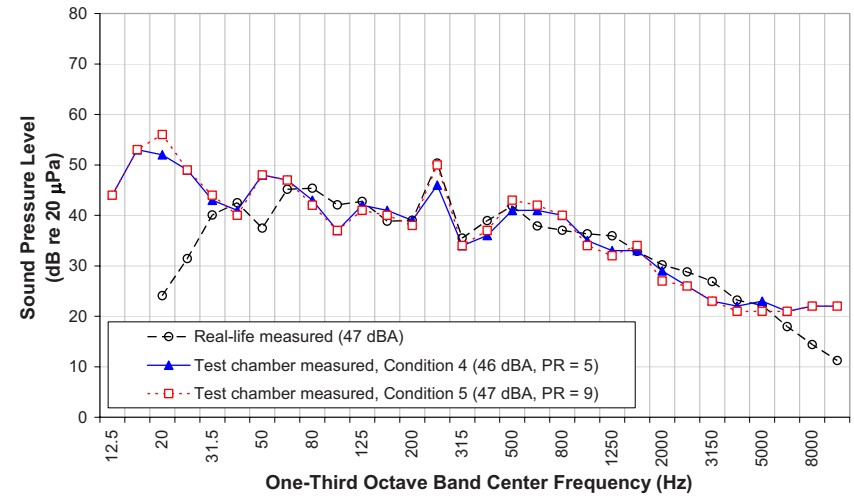

FIG. 4. (Color online) One-third octave band spectrum of $235 \mathrm{~Hz}$ tonal noise conditions (4) $(\mathrm{PR}=5)$ and (5) $(\mathrm{PR}=9)$, as measured in the real installation and in the test chamber.

the prominence limit at $\mathrm{PR}=5$ and $\mathrm{PR}=9$. However, more recent research indicates that even higher PR values may be required for a tone to be considered prominent, particularly for lower frequencies. ${ }^{46}$

The measurements shown in Figs. 2-5 were made at the test subject's location using a Larson Davis 824 sound level meter. The values shown represent an average of measurements taken at the two work stations over several measurement trials on multiple days. The difference between stations was no greater than $3 \mathrm{~dB} L_{\mathrm{Aeq}}$ on average and the sound field surrounding each subject was relatively uniform (to within $\left.3 \mathrm{~dB} L_{\text {Aeq }}\right)$.

Noise condition (1) was simulated in previous work..$^{10,47}$ Conditions (2)-(6) were recordings. Some manipulation of these recorded signals was necessary, primarily because the equalization of the system had to remain preset at certain levels across frequency to facilitate automated playback. The noise conditions were calibrated by digitally filtering the raw recorded audio files by using COOL EDIT 2000 software until the one-third octave band equivalent sound pressure levels measured in the test chamber closely matched those recorded in the real-life spaces, as shown in Figs. 3-5.

The indoor noise criteria ratings calculated for the six noise conditions are provided in Table I. Although the tonal frequency and prominence differed between the noise conditions, there was little difference in the noise criteria ratings due to the overall sound levels being similar.

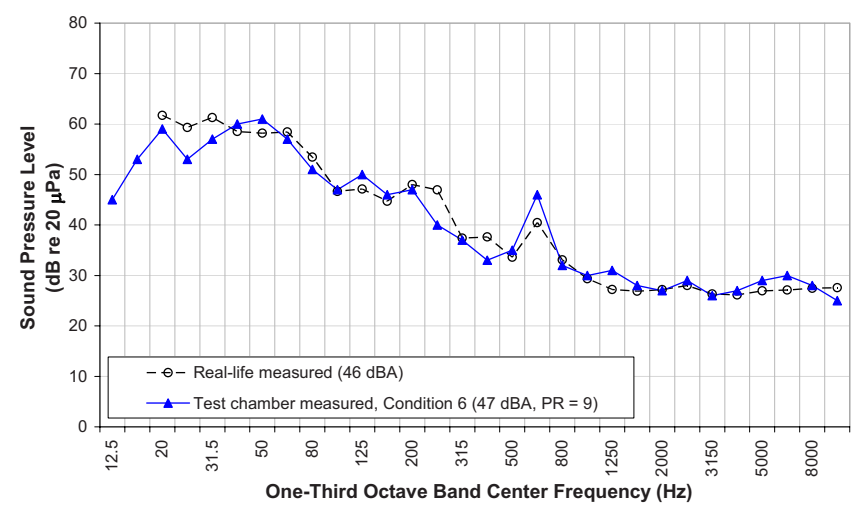

FIG. 5. (Color online) One-third octave band spectrum of $595 \mathrm{~Hz}$ tonal noise condition (6) $(\mathrm{PR}=9)$, as measured in the real installation and in the test chamber.

E. E. Ryherd and L. M. Wang: Implications of tonal response on criteria 
TABLE I. Indoor noise criteria ratings of the six noise conditions used. $\mathrm{N}=$ neutral, $\mathrm{R}=$ rumbly, $\mathrm{H}=\mathrm{hissy}, \mathrm{V}$ = vibrational, $\mathrm{LF}=$ excessive low frequency, $\mathrm{MF}=$ excessive midfrequency, $\mathrm{HF}=$ excessive high frequency.

\begin{tabular}{|c|c|c|c|c|c|}
\hline \multirow[b]{2}{*}{ Noise condition } & \multicolumn{5}{|c|}{ Indoor noise Criteria rating } \\
\hline & $\mathrm{NC}$ & $\mathrm{NCB}$ & $\mathrm{RC}$ & RC mark II & $L_{\text {Aeq }}$ \\
\hline Midlevel neutral & 40 & $38 \mathrm{~N}$ & $40 \mathrm{~N}$ & $\begin{array}{l}40 \mathrm{HF} \text {, } \\
\text { marginal }\end{array}$ & 47 \\
\hline $120 \mathrm{~Hz}$ tonal, $P R=5$ & 40 & $38 \mathrm{~N}$ & $41 \mathrm{~N}$ & $\begin{array}{l}41 \mathrm{HF} \text {, } \\
\text { marginal }\end{array}$ & 47 \\
\hline $120 \mathrm{~Hz}$ tonal, $P R=9$ & 44 & $38 \mathrm{R}$ & $41 \mathrm{~N}$ & $\begin{array}{l}41 \mathrm{HF}, \\
\text { marginal }\end{array}$ & 48 \\
\hline $235 \mathrm{~Hz}$ tonal, $P R=5$ & 41 & $37 \mathrm{H}$ & $40 \mathrm{~N}$ & $\begin{array}{c}40 \mathrm{HF}, \\
\text { objectionable }\end{array}$ & 46 \\
\hline $235 \mathrm{~Hz}$ tonal, $P R=9$ & 42 & $37 \mathrm{R}, \mathrm{H}$ & $41 \mathrm{~N}$ & $\begin{array}{l}41 \mathrm{HF}, \\
\text { marginal }\end{array}$ & 47 \\
\hline $595 \mathrm{~Hz}$ tonal, $P R=9$ & 43 & $37 \mathrm{R}, \mathrm{H}$ & $39 \mathrm{H}$ & $\begin{array}{c}39 \mathrm{~N}, \\
\text { acceptable }\end{array}$ & 47 \\
\hline
\end{tabular}

\section{Subjects}

Thirty subjects ( 15 male and 15 female) participated in this study. The subjects were prescreened in accordance with methods previously used by the authors. ${ }^{47}$ A GSI 17 audiometer was used to verify that all the subjects had hearing thresholds below $25 \mathrm{~dB}$ hearing level from $125 \mathrm{~Hz}$ to $8 \mathrm{kHz}$. A Keystone ophthalmic telebinocular was used to evaluate visual function. All subjects were found to have a minimum typing ability of $20 / \mathrm{min}$ words by using SKILLCHECK software.

\section{Experimental procedure}

Each subject attended six 55 min sessions on six separate days, with each subject scheduled at approximately the same time on all days when possible. The session length was selected based on previous research by the authors that examined the influence of exposure time on task performance and questionnaire results. ${ }^{47}$ Results from the previous study indicated that performance did not change significantly over testing sessions ranging from $20 \mathrm{~min}$ to $4 \mathrm{~h}$, but shorter noise exposures $(20 \mathrm{~min})$ may have allowed for more comparison between sequential noise conditions. Therefore, in this study, subjects were only exposed to a single noise condition per testing day to minimize biasing effects.

A flowchart of the experimental procedure for a single testing session is shown in Fig. 6. Subjects completed paperbased tasks for the first $25 \mathrm{~min}$. These tasks were developed from the verbal portion of the Graduate Record Examination (GRE) test. To limit the total amount of data collected, these tests were not scored, although subjects were operating under the assumption that they would be. The intent was to allow subjects to adjust to the background noise while staying mentally active. Two sequences of task performance tests and a subjective rating portion followed the paper-based task. Two subjects completed testing at the same time whenever possible and were not allowed to communicate with each other during testing.

\section{E. Performance tasks}

Task performance was evaluated under each noise condition using three types of computer-based tests developed in previous work by the authors. ${ }^{47}$ Participants in the previous study were excluded from participating in the current study. The testing software was developed by the SKILLCHECK company. ${ }^{48}$ Multiple versions of each task were developed and all subjects completed all versions of the tests with the order of presentation randomized for each subject. The multiple versions were carefully developed to be approximately equal in length and difficulty based on standardized testing metrics. $^{47}$

The typing test required the subjects to retype printed paragraphs. Analysis of these tasks was based on the net typing speed, which accounted for the typing speed and the number of errors made. The grammatical reasoning task required the subjects to determine if a given statement correctly described the order of a letter sequence. ${ }^{40,42,49}$ For example, the subject may have been presented with the following: $\mathrm{CA}-\mathrm{C}$ is before A (true or false). The answer is "true" because the sentence correctly describes the letter combination. The math task consisted of math statements and short word problems. Subjects were allowed to use paper and pencil, but no calculators.

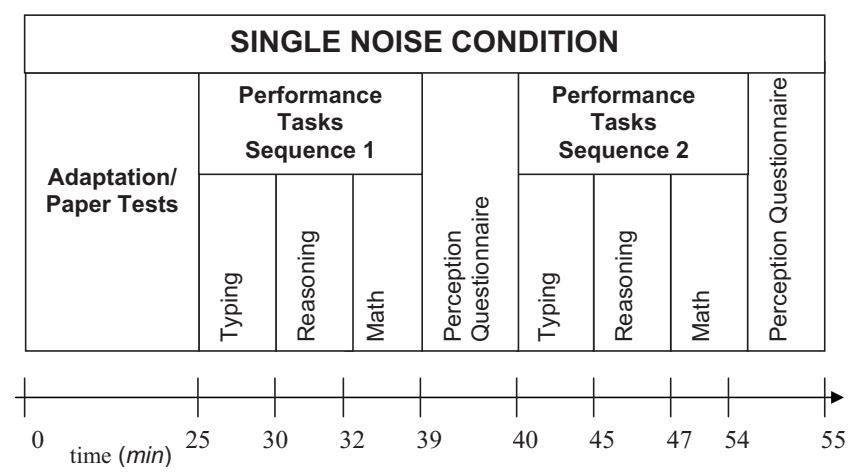

FIG. 6. The experimental sequence in time for a single noise condition. $25 \mathrm{~min}$ of adaptation were followed by $30 \mathrm{~min}$ of performance testing and perception rating questionnaires, for a total time of $55 \mathrm{~min}$. 


\section{F. Subjective perception questionnaire}

After each set of computer tasks, subjects completed a questionnaire about their perception of the testing environment. The questionnaires were developed in previous research by the authors. ${ }^{47}$ Eight noise questions asked specifically about loudness, rumble, roar, hiss, tonality, fluctuations over time, distraction, and annoyance. Subjects were also asked five questions about air freshness, temperature comfort, air movement, lighting, and work station comfort. The only factor changing in the room was the noise; temperature, lighting, etc., were all controlled to be relatively constant, although subjects did not know what specifically was changing in the room. The additional questions on the non-noise conditions were included to divert attention somewhat away from the acoustics. Estimations were based on a seven-point discrete scale.

Prior to the testing session, subjects completed a training module in which they were exposed to several of the questionnaire terms. The module described "rumbly," "roaring," and "hissy" noise as containing excessive low, mid-, and high frequencies, respectively. They listened to corresponding audio samples of band-limited white noise covering the $16-63 \mathrm{~Hz}, 125-500 \mathrm{~Hz}$, and $1-8 \mathrm{kHz}$ octave bands. They also listened to a "tonal" broadband noise with a tone at $500 \mathrm{~Hz}$. No specific instructions were given on any other descriptors included in the questionnaire.

\section{RESULTS}

Linear mixed models, analysis of variance (ANOVA), and Pearson product moment correlations $(r)$ were used to assess the differences in performance task scores, subjective ratings, and noise criteria predictions using SPSS software. ${ }^{50,51}$

\section{A. Subjective perception questionnaires versus criteria level ratings}

Subjective perception of loudness, annoyance, distraction, rumble, roar, hiss, fluctuations, and tonality were compared to the criteria level ratings. Very few statistically significant relationships were found, in part because the criteria level ratings were not changing markedly, as shown in Table I. Conditions with higher $L_{A \text { eq }}$ were perceived as louder ( $F$ =4.96, $p<0.05)$, more annoying $(F=3.83, p<0.05)$, and more rumbly $(F=8.69, p<0.01)$. These results agree with a previous study by the authors. ${ }^{10}$

Conditions with higher $\mathrm{RC}$ and $\mathrm{RC}$ mark II level ratings were perceived as more roaring $(F=4.86, p<0.05)$ and less hissy $(F=39.97, p<0.01)$. It might be expected that some of the conditions with the highest RC mark II level ratings would be rated as roaring based on the perception rating, but this was not the case. RC does not provide a roaring descriptor. Based on the perception results, it might also be expected that some of the conditions with the lowest RC and RC mark II level ratings would be rated as hissy. Interestingly, the condition with the lowest RC and RC Mark II level rating [condition (6): high frequency tonal, $595 \mathrm{~Hz}, \mathrm{PR}=9$ ] was rated hissy by RC but not by RC mark II.
Conditions with higher NC level ratings were perceived as more tonal $(F=7.46, p<0.01)$ and fluctuating $(F=9.56$, $p<0.01)$ by subjects. Possibly there is some link between perception of fluctuation and tones or the spectral quality of these conditions. The tonal finding makes sense based on the NC level ratings shown in Table I. NC levels were slightly higher for tonal conditions (3)-(6) as compared to the nontonal condition (1). The $\mathrm{NC}$ rating also increases slightly as the PR increases from condition $(2)(120 \mathrm{~Hz}$ tonal, $\mathrm{PR}=5)$ to condition (3) $(120 \mathrm{~Hz}$ tonal, $\mathrm{PR}=9)$ and from condition (4) $(235 \mathrm{~Hz}$ tonal, $\mathrm{PR}=5)$ to condition (5) $(235 \mathrm{~Hz}$ tonal, PR $=9$ ). Although the NC rating appears to be sensitive to tonality in this study, it still may not be an ideal choice of descriptors for all tonal environments. A tonal component in an octave band can dictate the overall rating due to the tangential nature of the NC methodology. In background noise scenarios where the tones are even more prominent than those presented in this study, the NC level rating may shift to a level rating that is not representative of the perceived overall loudness of the background noise. Also, as will be shown later in Sec. IV C 2, condition (1) (NC 40) was perceived as significantly louder than two other conditions with similar criteria ratings [condition (2), NC 40 and condition (4), NC 41].

\section{B. Task performance results}

\section{Task performance versus criteria level ratings}

No significant relationships were found between typing, reasoning, and math scores and individual criterion predictions of level. This result is in agreement with previous research by the authors which used 12 nontonal conditions and different types of performance tasks. ${ }^{10,11}$ In previous work, it was hypothesized that the fact that performance scores were not significantly related to the criteria ratings may indicate that these criteria do not fully reflect occupant response to background noise. In this study, however, caution must be used in interpreting results due to the small change in the criteria level ratings as previously mentioned.

\section{Task performance versus subjective perception}

Previous research by the authors indicated that performance and perception were related to each other. ${ }^{10,11,47} \mathrm{Ex}-$ ample significant results from current study are depicted in Figs. 7 and 8 and summarized below:

- Typing performance decreased as subjects perceived the noise to be more distracting $(F=18.75, p<0.01)$, more annoying $(F=14.19, p<0.01)$, more rumbly $(F=13.52, p$ $<0.01)$, more roaring $(F=5.21, p<0.05)$, or more fluctuating $(F=3.81, p<0.05)$. These trends are in the expected direction.

- Reasoning task performance decreased as subjects perceived the noise to be more rumbly $(F=4.81, p<0.05)$. This trend is in the expected direction. However, performance improved as subjects perceived noise as more roaring $(F=7.19, p<0.01)$ or more hissy $(F=25.86, p<0.01)$.

- Math task performance improved as subjects perceived the noise to be more roaring $(F=9.45, p<0.01)$ or more hissy $(F=8.91, p<0.01)$.

E. E. Ryherd and L. M. Wang: Implications of tonal response on criteria 


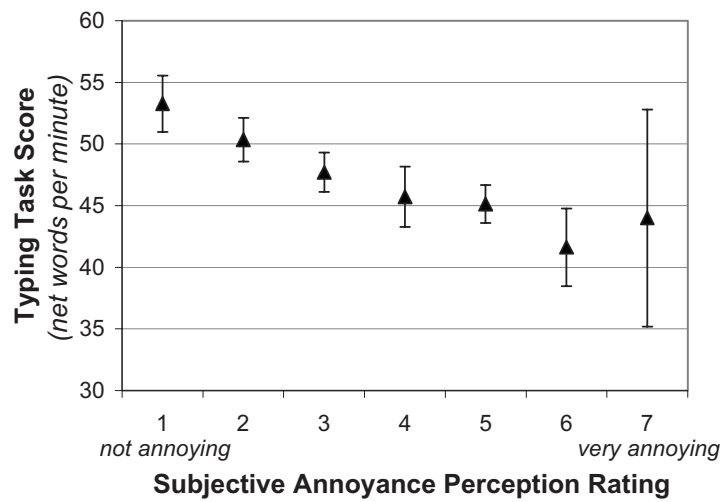

FIG. 7. Subjective annoyance perception ratings, averaged across all subjects and conditions vs typing task score. Net typing speed decreased as subjects perceived noise as more annoying $(p<0.01)$. Standard error of the mean bars are shown. The larger error bars indicate more variability in the data at these points; nonetheless, the overall trends were significant.

As shown in Fig. 7, typing speed slowed down as subjects perceived noise as more annoying. This result is in agreement with previous research by the authors which used 12 nontonal conditions and different types of performance tasks. ${ }^{10,11}$

Figure 8 shows the reasoning task scores improving as subjects perceived the noise as more roaring. This result is quite interesting when compared to previous research by the authors that examined primarily nontonal background noises. ${ }^{47}$ In both the current study and the previous one, math and reasoning performance improved with perception of increasing roar, while typing performance decreased. Given the repeatability of these results, it is possible that performance was negatively impacted by midfrequency noise perception on the more routine task (i.e., typing), whereas subjects were forced to concentrate on the more difficult tasks (i.e., reasoning and math) and therefore performed better. However, as stated in an earlier publication, one should not conclude that more roaring spectra necessarily produce better performance on certain tasks. ${ }^{10}$ Instead, one may conclude that the test subjects participating in this laboratory study wished to per-

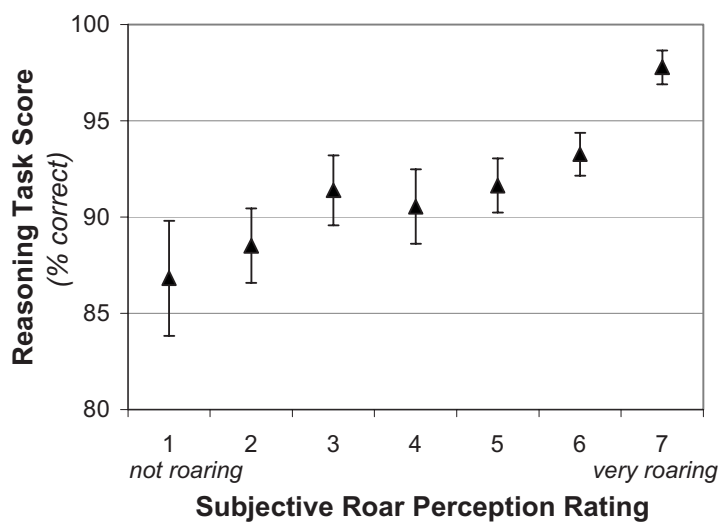

FIG. 8. Subjective roar perception ratings, averaged across all subjects and conditions vs reasoning task score. Reasoning performance scores increased as subjects perceived noise as more roaring $(p<0.01)$. Standard error of the mean bars are shown.

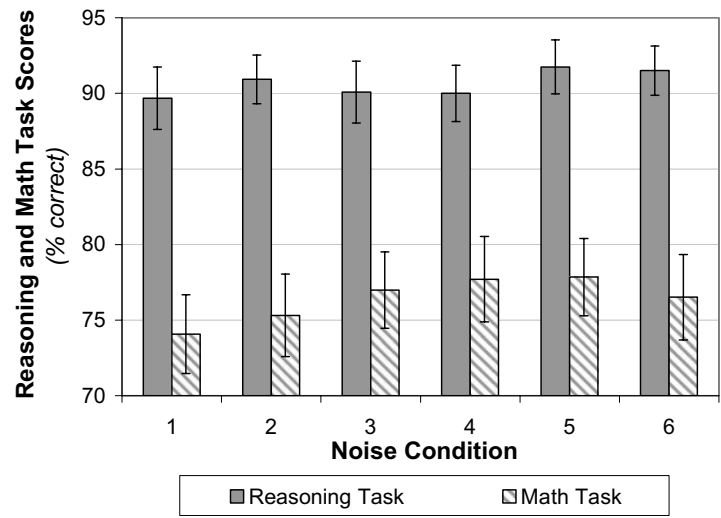

FIG. 9. Mean reasoning and math task scores, averaged across all subjects for each noise condition. The difference in performance scores across noise conditions was not statistically significant. Similarly, differences in typing task scores were nonsignificant. Standard error of the mean bars are shown.

form well on their tasks and may have produced better test scores by concentrating harder on specific tasks in the roaring scenarios presented in these studies.

\section{Influence of noise condition}

Also of interest was whether significant differences in task performance scores and subjective perception ratings existed between the various noise conditions despite their similar criteria ratings. This section contains results of ANOVA, Mauchly's sphericity, and Bonferroni post hoc tests. $^{50,51}$

\section{Noise condition vesus task performance}

Results showed no significant effect of noise condition on task performance scores. Figure 9 shows the reasoning and math task scores averaged across all subjects for each of the six noise conditions. The change in scores between different noise conditions is not statistically significant. Similar nonsignificant results were obtained for the typing task. It might be expected that subjects would perform worse when comparing any of tonal conditions (2)-(6) to nontonal condition (1), when comparing a less prominent tonal condition to a more prominent tonal condition [such as from conditions (2) and (3) or from conditions (4) and (5)]. Trend directions were as expected in some instances and not in others.

Previous work has demonstrated that the types of noises being compared can largely influence results. Landström et al. found no significant difference in performance on a figure identification test when comparing a broadband ventilation noise to a second broadband ventilation noise with a tone added at $100 \mathrm{~Hz}$ (both at $L_{\mathrm{Aeq}}=40 \mathrm{dBA}$ ). ${ }^{30}$ However, when comparing the tonal noise to the same noise with a masking pink noise (41 dBA) added in the frequency range of $50-200 \mathrm{~Hz}$, they found a tendency toward better performance, higher wakefulness, higher annoyance, and lower tolerated levels under the pink noise added exposure. ${ }^{30}$ The fact that differences were seen when comparing the tonal noise to the masked noise but not when comparing the tonal noise to the broadband noise indicates that the types of noise conditions used play a strong role. In the current research project, more obvious differences in task performance across the 
TABLE II. Example statistically significant differences in perception between the six noise conditions used, ${ }^{*} p<0.05$.

\begin{tabular}{|c|c|c|}
\hline $\begin{array}{l}\text { Subjective } \\
\text { perception } \\
\text { descriptor }\end{array}$ & \multicolumn{2}{|c|}{$\begin{array}{l}\text { Statistically significant perception differences } \\
\text { between noise conditions }\end{array}$} \\
\hline Annoyance & $\begin{array}{l}\text { (1) Midlevel neutral } \\
\text { was more annoying than } \rightarrow\end{array}$ & $\begin{array}{c}\text { Condition }(4) \\
(235 \mathrm{~Hz} \text { tonal, } \mathrm{PR}=5)\end{array}$ \\
\hline Loudness & $\begin{array}{c}\text { (1) Midlevel neutral } \\
\text { was louder than } \rightarrow \\
\text { and } \rightarrow\end{array}$ & $\begin{array}{c}\text { Condition }(2) \\
(120 \mathrm{~Hz} \text { tonal, } \mathrm{PR}=5) \\
\text { Condition }(4) \\
(235 \mathrm{~Hz} \text { tonal, } \mathrm{PR}=5)\end{array}$ \\
\hline Tonality & $\begin{array}{c}\text { (3) } 120 \mathrm{~Hz} \text { tonal, } \mathrm{PR}=9 \\
\text { was more tonal than } \rightarrow \\
\text { (5) } 235 \mathrm{~Hz} \text { tonal, } \mathrm{PR}=9 \\
\text { was more tonal than } \rightarrow \\
\text { and } \rightarrow\end{array}$ & $\begin{array}{c}\text { Condition }(4) \\
(235 \mathrm{~Hz} \text { tonal, } \mathrm{PR}=5) \\
\text { Condition }(1) \\
\text { (midlevel neutral) } \\
\text { Condition }(4) \\
(235 \mathrm{~Hz} \text { tonal, } \mathrm{PR}=5)\end{array}$ \\
\hline
\end{tabular}

various noise conditions may have been observed with greater differences in the PR between the paired signals.

It is also apparent in examining Fig. 9 that the subjects scored higher overall on the reasoning task. This result is in agreement with previous research by the authors. ${ }^{47} \mathrm{~A}$ more difficult administration of this task or the others may have resulted in greater variance in scores under the different noise conditions.

\section{Noise condition versus subjective perception}

An analysis was conducted to determine whether subjective perception of tonality, loudness, annoyance, and distraction differed from one noise condition to another. Example significant results are provided in Table II and are described below.

Figure 10 shows the mean subjective tonality and loudness perception ratings for the six noise conditions. Results showed a main effect of signal on subjective tonality perception ratings $(F=4.84, p<0.01)$. Although a significant difference in tonality was perceived between the paired $235 \mathrm{~Hz}$ tonal conditions [(4) and (5)], a difference was not significantly perceived between PRs for the lower frequency $120 \mathrm{~Hz}$ tonal conditions [(2) and (3)]. This falls in line with

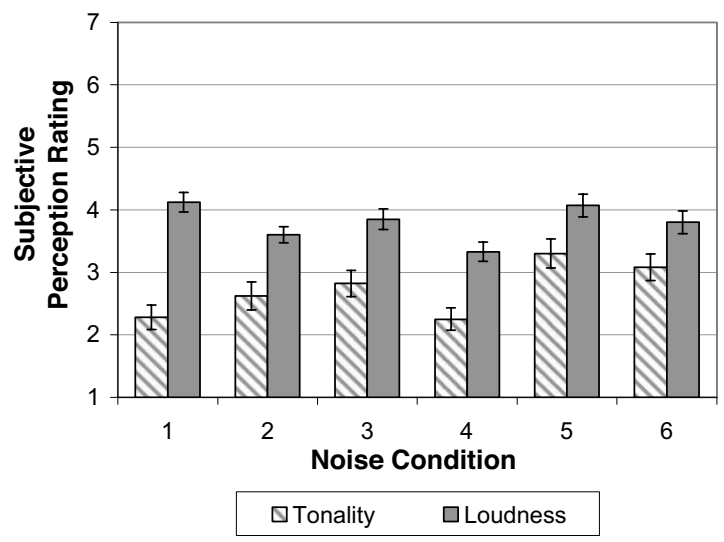

FIG. 10. Mean subjective tonality and loudness perception ratings, averaged across all subjects for each noise condition. The tonality scale ranges from $1=$ no tones to $7=$ very noticeable tones, and the loudness scale ranges from $1=$ very quiet to $7=$ very loud. Standard error of the mean bars are shown.
Hellweg, Jr. and Nobile's study which determined that low frequencies require a higher PR for the tone to be considered prominent (around $18 \mathrm{~dB}$ for $120 \mathrm{~Hz}$ ). ${ }^{46}$ As shown in Fig. 10 , the general trend direction was for condition (3) to be perceived as more tonal than condition (2).

Tonality perception results also indicated that condition (5) $(235 \mathrm{~Hz}$ tonal) with a higher PR was more tonal than the neutral noise [condition (1)]. Not all of the tonal conditions were perceived as significantly more tonal than condition (1), though, which again supports the higher PR values recommended for tonal prominence by Hellweg, Jr. and Nobile. ${ }^{46}$ As shown in Fig. 10, the general trend direction was for the tonal conditions to be perceived as more tonal than condition (1), with the exception of condition (4) (midfrequency tonal noise, $235 \mathrm{~Hz}, \mathrm{PR}=5$ ).

Results showed a main effect of signal on subjective loudness perception ratings $(F=3.40, p<0.05)$. The neutral noise [condition (1)] was perceived as louder than the two $\mathrm{PR}=5$ tonal conditions [conditions (2) and (4)]. This indicates that the overall level of the broadband frequency component had to be louder to compensate for the tonal contribution. Thus it makes sense that the PR of 5 for conditions (2) and (4) was not enough to "match" the loudness of condition (1), but with the PR of 9 [as seen in conditions (3), (5), and (6)], the loudness is perceived as approximately equal to broadband condition (1).

Results also showed a main effect of signal on subjective annoyance $(F=2.57, p<0.05)$ and distraction perception ratings $(F=2.32, p<0.05)$. The trends for the mean subjective annoyance and distraction perception ratings were similar to the loudness trend shown in Fig. 10. Although statistically significant relationships were not observed, the general trends were for the mean annoyance and distraction perception ratings to be higher for the $\mathrm{PR}=9$ exposures as compared to their $\mathrm{PR}=5$ counterparts. However, the trend showed that tonal conditions (2)-(6) were not perceived as generally more annoying or distracting than condition (1). Previous studies have shown that a pure tone in noise can make the noise more annoying. ${ }^{27,31}$ For example, Landström et al. found that annoyance increased when comparing a broadband noise to a tonal noise. ${ }^{31}$ The effect was more prominent with a high frequency $(1000 \mathrm{~Hz})$ tone, whereas the effects of a low frequency $(100 \mathrm{~Hz})$ tone were more unclear. It is possible that in this study, because subjects perceived condition (1) as being approximately as loud or louder than conditions (3), (5), and (6) (as shown in Fig. 10), they also perceived condition (1) as being equally or more annoying and distracting than the nontonal conditions.

Differences in annoyance may have also been expected when comparing the tonal frequencies $(120,235,595 \mathrm{~Hz})$. Landström et al. investigated which tonal frequencies in ventilation noise were found to be the least and most annoying. ${ }^{32}$ Subjects listened to a ventilation noise and were told to adjust a tone frequency at $40 \mathrm{dBA}$ to the lowest and highest annoyance within the frequency range of $35-500 \mathrm{~Hz}$. Subjects found $58 \mathrm{~Hz}$ to be the least annoying and $380 \mathrm{~Hz}$ to be the most annoying. The higher frequency was also correlated to higher discomfort and lower performance. Despite the lack of significant findings, the trend in the current study was 
for condition (5) $(235 \mathrm{~Hz}$ tonal, $\mathrm{PR}=9)$ to be perceived as slightly more annoying and distracting than the other tonal noise conditions (120 and $595 \mathrm{~Hz}$ ).

\section{CONCLUSIONS}

The influence of tones in background noise on human task performance and subjective perception and the relationship to noise criteria was analyzed in this study. As in previous research, clear relationships between performance and criteria level predictions were not observed. ${ }^{10,11}$ In addition, few statistically significant relationships existed between subjective perception and criteria level ratings. The lack of significant relationships may have been due in part to the fact that there was very little difference in the criteria level ratings of the signals. Subjective perception of noise was significantly related to task performance scores, though.

Although significant differences in performance were not observed between the noise conditions, there were some differences in perception. Statistically significant relationships were not observed in all the expected cases, but the perception trends were generally as expected with higher PR $(\mathrm{PR}=9)$ conditions perceived as more tonal, louder, more annoying, and more distracting than their counterpart PR $=5$ conditions. It appeared that the perceived loudness of the nontonal condition may have contributed to perceived annoyance and distraction of this condition. Therefore, a tradeoff between loudness and tonality perception is required to fully match perception of adverse response.

This study provided insight into how the tonality of background noise can impact task performance and perception. Overall, the indication is that although there were no significant differences in performance between the various noise conditions, there were differences in perception. These differences in perception are not adequately reflected in the criteria methods analyzed. Although the six noise conditions used in this study contained different tonal qualities, and were thus perceived as significantly different in some cases, there was essentially no change in the criteria level ratings across the noise conditions. Although there were minor changes in the criteria spectral quality descriptors across the noise conditions, it is difficult to relate these easily or accurately to tonality.

Putting performance aside for a time, if a primary goal of a criterion is to relate to occupant perception, the existing criteria should be modified to account for tonality, including frequency and prominence. However, more research is needed before specific modification recommendations can be made, using different noise scenarios, types of tasks, and noise metrics. Due to the few statistically significant tonality perception findings in this study, it would be advantageous to develop a criterion from a set of data that has a greater range of subjective response. Future work could include a greater variety of noise conditions that include changes in both level and tonality in addition to a wider range of tonal frequency and prominence.

Existing tonal metrics can be tested against the data, such as the PR, tone-to-noise ratio, ${ }^{44}$ the Joint Nordic method, ${ }^{52}$ or Aures' model of tonalness, all of which are detailed by Hastings et al. ${ }^{53}$ are also recommended. Depending on how well the tonal metrics are correlated with subjective response, it may then be possible to develop a combined criterion which accounts for both level and tonality. Another option would be to incorporate the tonal recommendation given by ANSI. ${ }^{14}$ This suggests that if a pure tone is detected in noise, then the tone level should be at least $5 \mathrm{~dB}$ less than the level in the octave band of the NCB or RC criterion curve in which it falls. However, this guideline has not been widely adopted or incorporated into design standards. Perhaps a numerical penalty could be applied to a criterion when this recommended guideline is not met.

The process of improving the noise criteria should continue as more information becomes available on how occupants respond to indoor noise. Ultimately, the goal of any background noise criterion is to accurately reflect occupant response to noise to ensure that acoustical problems in buildings are correctly diagnosed, abated, or prevented. Additional consideration of tonality and other acoustical factors not yet fully accounted for (such as variance over time) will improve the performance of these commonly used tools.

\section{ACKNOWLEDGMENTS}

This work has been supported by the American Society of Heating, Refrigerating, and Air-Conditioning Engineers (ASHRAE) RP-1322, the Institute of Noise Control Engineering (INCE) Martin Hirschorn IAC Prize, the University of Nebraska-Lincoln (UNL) Center for Building Integration, and a UNL Research Council Faculty Seed Grant. The authors are grateful for the assistance of Cathy Novak and Marc Choiniere in administering the subjective tests, and for the recording contributions of Warren Blazier, Norman Broner, Mark Fly, Jerry Lilly, and Mark Schaffer.

${ }^{1}$ L. Beranek, "Revised criteria for noise in buildings," Noise Control 3, 19-27 (1957).

${ }^{2}$ L. Beranek, "Balanced noise-criterion (NCB) curves," J. Acoust. Soc. Am. 86, 650-664 (1989).

${ }^{3} \mathrm{~W}$. Blazier, "Revised noise criteria for application in the acoustical design and rating of HVAC systems," Noise Control Eng. 16, 64-73 (1981).

${ }^{4} \mathrm{~W}$. Blazier, "RC Mark II: A refined procedure for rating the noise of heating, ventilating, and air-conditioning (HVAC) systems in buildings," Noise Control Eng. J. 45, 243-250 (1997).

${ }^{5}$ American National Standards Institute, Design Response of Weighting Networks for Acoustical Measurements: S 1.42-2001 (Acoustical Society of America, Melville, New York, 2001).

${ }^{6} \mathrm{~L}$. Beranek, "Applications of NCB and RC noise criterion curves for specification and evaluation of noise in buildings," Noise Control Eng. J. 45, 209-216 (1997).

${ }^{7}$ W. Blazier, "Noise control criteria for heating, ventilating, and airconditioning systems," in Handbook of Acoustical Measurements and Noise Control, edited by C. Harris (Acoustical Society of America, Melville, NY, 1998), Chap. 43, pp. 43.1-43.18.

${ }^{8}$ G. Tocci, "Room noise criteria-State of the art in the year 2000," Noise News Int. 8, 106-119 (2000).

${ }^{9}$ L. Wang and E. Bowden, "Performance review of indoor noise criteria," Architectural Engineering Institute 2003 Proceedings, Austin, TX, 2003, Vol. 116, No. 2.

${ }^{10} \mathrm{E}$. Bowden and L. Wang, "Relating human productivity and annoyance to indoor noise criteria systems: A low frequency analysis," ASHRAE Winter Meeting Transactions, Orlando, FL, 2005, Vol. 111, Issue 1, pp. 684-692.

${ }^{11}$ E. Bowden, "Investigations of indoor noise criteria systems based on human perception and task performance," Ph.D. thesis, University Nebraska, 2006.

${ }^{12}$ American Society of Heating, Refrigerating and Air-Conditioning Engi- 
neers, Inc., "Sound and vibration control," 2007 ASHRAE HVAC Applications Handbook (American Society of Heating, Refrigerating and AirConditioning Engineers, Atlanta, GA, 2003), Chap. 47, pp. 47.30-47.35.

${ }^{13}$ L. Goodfriend, RP-126: A Study to Update Indoor Sound Criteria for Air Conditioning Systems (American Society of Heating, Refrigerating and Air-Conditioning Engineers, Atlanta, GA, 1975).

${ }^{14}$ American National Standards Institute, Criteria for Evaluating Room Noise: S 12.2-1995 (Acoustical Society of America, Melville, NY, 1995).

${ }^{15}$ American National Standards Institute, Acoustical Performance Criteria, Design Requirements, and Guidelines for Schools: $S$ 12.60-2002 (Acoustical Society of America, Melville, NY, 2002).

${ }^{16}$ ISO-DIS 12001, "Draft glossary of terms used in noise control engineering," Noise News Int. 3, 161-168 (1995).

${ }^{17}$ K. Persson, M. Bjorkman, and R. Rylander, "An experimental evaluation of annoyance due to low frequency noise," Low Freq. Noise, Vib., Act. Control 4, 145-153 (1985).

${ }^{18}$ S. Tang, J. Burnett, and C. Poon, "Aural environment survey in airconditioned open-plan offices," Build. Services Eng. Res. Technol. 17, 97-100 (1996).

${ }^{19} \mathrm{~S}$. Tang, "Performance of noise indices in air-conditioned landscaped office buildings," J. Acoust. Soc. Am. 102, 1657-1663 (1997).

${ }^{20} \mathrm{~S}$. Tang and C. Wong, "Performance of noise indices in office environment dominated by noise from human speech,” Appl. Acoust. 55, 293-305 (1998).

${ }^{21} \mathrm{~S}$. Tang and M. Wong, "On noise indices for domestic air conditioners," J. Sound Vib. 274, 1-12 (2004).

${ }^{22}$ U. Ayr, E. Cirillo, and F. Martellotta, "An experimental study on noise indices in air conditioned offices," Appl. Acoust. 62, 633-643 (2001).

${ }^{23}$ U. Ayr, E. Cirillo, I. Fato, and F. Martellotta, "A new approach to assessing the performance of noise indices in buildings," Appl. Acoust. 64, 129-145 (2003).

${ }^{24}$ P. Susini, S. McAdams, S. Winsberg, I. Perry, S. Vieillard, and X. Rodet, "Characterizing the sound quality of air-conditioning noise," Appl. Acoust. 65, 763-790 (2004).

${ }^{25} \mathrm{~K}$. Persson Waye and R. Rylander, "The prevalence of annoyance and effects after long-term exposure to low-frequency noise," J. Sound Vib. 240, 483-487 (2001).

${ }^{26} \mathrm{~N}$. Broner, "Considerations in the rating and assessment of low-frequency noise," ASHRAE Annual Meeting Transactions, Denver, CO, Vol. 99, Issue 2, pp. 1025-1030 (1993).

${ }^{27}$ K. Kryter and K. Pearsons, "Judged noisiness of a band of random noise containing an audible pure tone," J. Acoust. Soc. Am. 38, 106-112 (1965).

${ }^{28} \mathrm{R}$. Hellman, "Loudness, annoyance, and noisiness produced by singletone-noise complexes," J. Acoust. Soc. Am. 72, 62-73 (1982).

${ }^{29}$ R. Hellman, "Perceived magnitude of two-tone complexes: Loudness, annoyance, and noisiness," J. Acoust. Soc. Am. 77, 1497-1504 (1985).

${ }^{30}$ U. Landström, A. Kjellberg, L. Söderberg, and B. Nordström, "The effects of broadband, tonal, and masked ventilation noise on performance, wakefulness and annoyance," Low Freq. Noise, Vib., Act. Control 10, 112-122 (1991).

${ }^{31}$ U. Landström, A. Kjellberg, and M. Byström, “Acceptable levels of sounds with different spectral characteristics during the performance of a simple and complex nonauditory task," J. Sound Vib. 160, 533-542 (1993).

${ }^{32}$ U. Landström, A. Kjellberg, L. Söderberg, and B. Nordström, "Measures against ventilation noise-which tone frequencies are least and most annoying?," Low Freq. Noise, Vib., Act. Control 13, 81-88 (1994).

${ }^{33} \mathrm{~K}$. Kryter, "Mental and psychomotor task performance in noise," The
Effects of Noise on Man (Academic, New York, NY, 1985), Chap. 9, pp. 343-387.

${ }^{34}$ D. Jones and D. Broadbent, "Human performance and noise," in Handbook of Acoustical Measurements and Noise Control, edited by C. Harris (Acoustical Society of America, Melville, NY, 1998), Chap. 24, pp. 24.124.24.

${ }^{35}$ M. Muzammil and F. Hasan, "Human performance under the impact of continuous and intermittent noise in a manual machining task," Noise Vib. Control Worldw. 35(7), 10-15 (2004).

${ }^{36} \mathrm{~K}$. Kyriakides and H. G. Leventhall, "Some effects of infrasound on task performance," J. Sound Vib. 50, 369-388 (1977).

${ }^{37}$ S. Benton and H. G. Leventhall, "Experiments into the impact of low level, low frequency noise upon human behaviour," Low Freq. Noise, Vib., Act. Control 5, 143-162 (1986).

${ }^{38}$ S. Benton and G. Robinson, "The effects of noise on text problem solving for the word processor user (WPU)," Proceedings of the Sixth International Congress: Noise as a Public Health Problem, Nice, France, 1993, pp. 539-541.

${ }^{39}$ K. Holmberg, U. Landström, and A. Kjellberg, "Effects of ventilation noise due to frequency characteristic and sound level," Low Freq. Noise, Vib., Act. Control 16, 115-122 (1993).

${ }^{40}$ K. Persson Waye, R. Rylander, S. Benton, and H. G. Leventhall, "Effects on performance and work quality due to low frequency ventilation noise," J. Sound Vib. 205, 467-474 (1997).

${ }^{41}$ K. Persson Waye, R. Rylander, J. Bengtsson, A. Clow, F. Hucklebridge, and P. Evans, "Does low frequency noise induce stress?," Proceedings of the Ninth International Low Frequency Noise and Vibration Meeting, Aalborg, Denmark, pp. 203-209 (2000).

${ }^{42}$ K. Persson Waye, J. Bengtsson, A. Kjellberg, and S. Benton, "Low frequency noise "pollution" interferes with performance," Noise Health $\mathbf{4}$, 33-49 (2001).

${ }^{43}$ J. Bengtsson, K. Persson Waye, A. Kjellberg, and S. Benton, "Low frequency noise "pollution" interferes with performance," Proceedings of the Ninth International Low Frequency Noise and Vibration Meeting, Aalborg, Denmark, pp. 15-21 (2000).

${ }^{44}$ American National Standards Institute, Measurement of Sound Pressure Levels in Air: S 1.13-1995 (Acoustical Society of America, Melville, NY, 1995).

${ }^{45}$ National Aeronautics and Space Administration, Auditory Demonstrations in Acoustics and Hearing Conservation CD (NASA Glenn Research Center, Cleveland, OH, 2004).

${ }^{46}$ R. D. Hellweg, Jr. and M. Nobile, "Modification to procedures for determining prominent discrete tones," Proceedings of Internoise, Dearborn, MI, 2002, Vol. 111, Issue 1, pp. 1707-1714.

${ }^{47}$ E. Ryherd and L. Wang, "Effects of exposure duration and type of task on subjective performance and perception in noise," Noise Control Eng. 55, 334-347 (2007).

${ }^{48}$ SkillCheck ${ }^{\mathrm{TM}}$ Corporation, 2007 (http://www.skillcheck.com).

${ }^{49} \mathrm{~A}$. Baddeley, "A 3 min reasoning test based on grammatical transformation," Psychonomic Sci. 10, 341-342 (1968).

${ }^{50}$ SPSS ${ }^{\mathrm{TM}}$ Corporation, 2007 (http://www.spss.com).

${ }^{51}$ A. Field and G. Hole, How to Design and Report Experiments (Sage, London, 2003)

52" Objective method of assessing the audibility of tones in noise," Delta report AV on the Joint Nordic method, Version 2, 1952/99.

${ }^{53}$ A. Hastings, K. Lee, P. Davies, and A. Surprenant, "Measurement of the attributes of complex tonal components commonly found in product sound,” Noise Control Eng. J. 51, 195-209 (2003). 